\title{
Farelo de trigo e complexo enzimático na alimentação de poedeiras semipesadas na fase de produção ${ }^{1}$
}

\author{
Daniel de Magalhães Araujo ${ }^{1 *}$, José Humberto Vilar da Silva ${ }^{2}$, Edma Carvalho de Miranda ${ }^{3}$, José \\ Anchieta de Araujo ${ }^{1}$, Fernando Guilherme Perazzo Costa ${ }^{4}$, Elisanie Neiva Magalhães Teixeira ${ }^{1}$ \\ ${ }^{1}$ Pós-graduação em Zootecnia, PPGZ/CCA/UFPB, Areia - PB. \\ 2 DAP/CFT/UFPB, Bananeiras - PB e PPGZ, CCA/UFPB, Areia - PB. \\ 3 Instituto de Química e Biotecnologia da UFAL, Maceió - $A L$. \\ ${ }^{4}$ DZ/CCA/UFPB, Bananeiras - PB e PPGZ, CCA/UFPB, Areia - PB.
}

RESUMO - O estudo foi conduzido com o objetivo de avaliar os efeitos da inclusão de farelo de trigo (FT) na ração com ou sem a suplementação de um complexo enzimático (CE) sobre o desempenho e a produção de ovos de frangas semipesadas na fase de produção. Foram utilizadas 288 frangas Lohmann Brown, distribuídas em delineamento inteiramente casualizado, em esquema fatorial $4 \times 2$, composto de quatro níveis de farelo de trigo $(0,3,6$ e $9 \%)$ na ração e da suplementação de complexo enzimático ( 0 ou $100 \mathrm{~g} / 100 \mathrm{~kg}$ de ração), com oito tratamentos e seis repetições de seis aves. O complexo enzimático continha as enzimas $\beta$-galactosidase, galactomananase, xilanase e $\alpha$-glucanase. O consumo de ração, o peso vivo final, a produção de ovos, o peso e a massa de ovos e a conversão por massa e por dúzia de ovos não foram afetados pela inclusão do farelo de trigo nas rações. A gravidade específica da casca dos ovos piorou com o aumento dos níveis de farelo de trigo nas dietas. Nenhuma característica foi afetada pela adição do complexo enzimático na ração, com exceção do peso do ovo, que melhorou de 62,74 para 64,28 g. Recomenda-se o uso de até $9 \%$ de farelo de trigo em rações para poedeiras em produção. A adição de $\alpha$-galactosidase, galactomananase, xilanase e $\alpha$-glucanase aumenta o peso dos ovos.

Palavras-chave: alimento alternativo, enzimas exógenas, produção de ovos

\section{Wheat bran and enzymatic complex in the feeding of laying hens in the production phase}

\begin{abstract}
The study was carried out with the objective to evaluate the effects of the inclusion of the wheat bran (WB) with or without supplementation of an enzymatic complex (EC) on the performance of semi-heavy hens in the eggproduction phase. A total of 288 Lohmann Brown pullets were used, distributed to a completely randomized design in 4 $\times 2$ factorial arrangement, composed by four WB levels $(0,3,6$ and $9 \%)$ in the ration and enzymatic complex supplementation ( 0 or $100 \mathrm{~g} / 100 \mathrm{~kg}$ diet), with eight treatments and six replicates of six birds. The enzymatic complex contained the enzymes $\beta$-galactosidase, galactomananase, xilanase and $\alpha$-glucanase. Feed intake, final body weight, egg production, egg weight, egg mass, egg mass feed conversion or egg dozen feed conversion was not affected by WB inclusion in the diets. Egg shell specific gravitydeterioratedas WB levels increase in the diets. None of the characteristics was affected by the enzymatic complex supplementation, except for egg weight, that improved from 62.74 to $64.28 \mathrm{~g}$. Then, the use up to $9.0 \%$ of wheat bran in the ration is recommended for semi-heavily chickens in the production phase. The supplementation of $\alpha$-galactosidase, galactomannanase, xylanase and $\alpha$-glucanase improve egg weight.
\end{abstract}

Key Words: alternative feedstuff, egg production, exogenous enzymes

\section{Introdução}

O farelo de trigo é o principal e mais abundante subproduto da moenda de grãos e um recurso alimentar renovável (Beaugrand et al., 2004) ainda pouco explorado na fabricação de rações para aves. É utilizado pelas indús- trias na formulação de rações para aves reprodutoras e de postura, no entanto, não há dados precisos na literatura sobre os níveis adequados desse alimento nas dietas e seus efeitos sobre o desempenho produtivo das aves.

Esse subproduto apresenta bom nível de proteína $(15,52 \%$, com base na matéria natural), entretanto, possui

Este artigo foi recebido em 24/4/2007 e aprovado em 30/10/2007.

Correspondências devem ser enviadas para danielzootecnista@yahoo.com.br.

Endereço atual: Pós-Graduação em Zootecnia, Departamento de Melhoramento Zootécnico e Nutrição Animal, Universidade Estadual Paulista Júlio de Mesquita Filho, Faculdade de Medicina Veterinária e Zootecnia, Fazenda Experimental Lageado, Caixa Postal 560 - CEP: 18618-000 - Botucatu, SP. 
alta concentração de fibra $(9,66 \%$, com base na matéria seca), segundo Rostagno et al. (2005), o que limita sua adição em dietas para aves. De acordo com Maes et al. (2004), os principais polissacarídeos não-amídicos (PNA) presentes na fração fibrosa deste subproduto são as arabinoxilans (36,5\%), a celulose (11\%), a lignina (3 a 10\%) e os ácidos urônicos (3 a 6\%). A elevada proporção de PNA, notadamente as arabinoxilans, contitui um problema para a fisiologia digestiva das aves, pois, de acordo com Silva \& Smithard (2002), as aves não possuem enzimas endógenas capazes de digerir esses componentes, o que compromete a digestibilidade da dieta. A redução da digestibilidade diminui, conseqüentemente, a eficiência de utilização e a disponibilidade de alguns aminoácidos para a síntese de proteína corporal e a deposição de proteína no ovo (Silva et al., 2000), além de reduzir a energia metabolizável, piorando o desempenho e comprometendo ainda mais a produção de ovos.

As arabinoxilans do trigo causam inibição geral da digestão dos nutrientes, afetando a digestibilidade de carboidratos, gorduras e proteínas, o que pode ser explicado por um provável desarranjo da proteína e/ou por uma redução, ou até mesmo inibição, da absorção dos aminoácidos causada pelos fatores antinutricionais contidos nos PNA.Também pode resultar em aumento da secreção de proteínas endógenas derivadas do intestino, além de perda de células intestinais (Bedford \& Partridge, 2001).No farelo de trigo, em decorrência do processo de moenda, que retira o endosperma do grão, ficam contidos tecidos botânicos distintos, como o pericarpo (película que recobre o grão), a testa (película que recobre a semente), a camada hialina e a aleurona, onde há maior concentração de PNA.

A adição de enzimas apropriadas é capaz de reduzir algumas das propriedades anti-nutricionais desses PNA da parede celular (Yin et al., 2000), diminuir a variação da qualidade nutricional das dietas, permitir digestão mais rápida e completa, diminuindo a excreção fecal de nutrientes e, conseqüentemente, a poluição ambiental, além de reduzir a incidência de fezes úmidas quando as aves são alimentadas com dietas de alta vicosidade (Bedford, 2000). A inclusão de enzimas exógenas nas dietas também pode reduzir o alto investimento energético do animal para a síntese enzimática.

As enzimas específicas que têm mostrado benefícios para animais não-ruminantes são as xilanases para dietas à base de trigo, triticale e arroz e $\beta$-glucanases ou celulases para dietas à base de cevada e aveia (Marquardt et al., 1996), entretanto, a combinação de mais de uma enzima tem potencializado os efeitos benéficos sobre a digestibilidade.
A eficácia da suplementação enzimática tem sido bem estabelecida (Silva \& Smithard, 2002) e o uso de xilanases e $\beta$-glucanases tem se mostrado eficiente em melhorar o desempenho de aves alimentadas com dietas contendo ingredientes como trigo e cevada, que promovem o aumento da viscosidade, ou mesmo com milho e farelo de soja, considerados grãos que não promovem viscosidade (Mathlouthi et al., 2003a, b).

Objetivou-se com este trabalho avaliar os efeitos da inclusão de farelo de trigo, com ou sem adição de complexo enzimático, em rações para poedeiras semipesadas durante a fase de produção de ovos.

\section{Material e Métodos}

O experimento foi conduzido no Laboratório Avícola do Centro de Formação de Tecnólogos (CFT), Campus III da Universidade Federal da Paraíba (UFPB), situado no município de Bananeiras, na microrregião do Brejo paraibano. Foram utilizadas 288 poedeiras semipesadas da linhagem Lohmann Brown em primeiro ciclo de postura e peso vivo inicial de $1,735 \pm 0,060 \mathrm{~kg}$.

O galpão experimental, com orientação no sentido lesteoeste, apresentava cobertura de telhas de barro em duas águas, pé-direito de 1,8 $\mathrm{m}$ de altura, duas fileiras de gaiolas sobrepostas em três fileiras duplas, com dois corredores de $1 \mathrm{~m}$ de largura entre as três carreiras. As gaiolas utilizadas no alojamento de duas aves eram de arame galvanizado e mediam $25 \mathrm{~cm} \times 45 \mathrm{~cm} \times 40 \mathrm{~cm}$.

Inicialmente, as aves foram pesadas e distribuídas conforme o peso, para posterior acompanhamento da produção de ovos durante 15 dias. As parcelas foram então homogeneizadas pela produção de ovos, de modo que as poedeiras improdutivas foram substituídas progressivamente ao longo do período. Após a homogeneização da produção, as aves passaram a ser alimentadas com as rações experimentais e deu-se início à coleta de dados.

O delineamento experimental utilizado foi o inteiramente ao acaso, em esquema fatorial $4 \times 2$, composto de quatro níveis de farelo de trigo $(0,3,6$ e $9 \%)$ e da suplementação ou não de complexo de enzimático (0 e 100 g/100 kg de ração), o que resultou em oito tratamentos, cada um com seis repetições de seis aves, totalizando 48 unidades experimentais. O complexo enzimático $(\mathrm{CE})$ foi constituído pelas enzimas $\alpha$-galactosidase, galactomananase, xilanase e $\beta$-glucanase.

A ração do período pré-experimental continha $2.700 \mathrm{kcal}$ $\mathrm{EM} / \mathrm{kg}$ e $15,95 \%$ PB. As rações experimentais (Tabela 1) foram isoenergéticas $(2.750 \mathrm{kcal} / \mathrm{kg})$ e isoprotéicas $(15,62 \%$ 
Tabela 1 - Composições alimentar e nutricional das rações experimentais $^{1}$

\begin{tabular}{|c|c|c|c|c|}
\hline \multirow[t]{2}{*}{ Ingrediente } & \multicolumn{4}{|c|}{ Nível de farelo de trigo (\%) } \\
\hline & 0 & 3 & 6 & 9 \\
\hline Milho & 65,373 & 62,144 & 58,933 & 55,720 \\
\hline Farelo de soja & 21,586 & 21,159 & 20,654 & 20,150 \\
\hline Farelo de trigo & 0,000 & 3,000 & 6,000 & 9,000 \\
\hline Calcário & 9,723 & 9,738 & 9,752 & 9,767 \\
\hline Fosfato bicálcio & 1,523 & 1,494 & 1,466 & 1,438 \\
\hline L-lisina $\cdot \mathrm{HCl}$ & 0,051 & 0,054 & 0,061 & 0,067 \\
\hline DL-metionina & 0,179 & 0,183 & 0,187 & 0,192 \\
\hline Óleo vegetal & 0,650 & 1,354 & 2,072 & 2,789 \\
\hline Supl. vitamínico ${ }^{2}$ & 0,100 & 0,100 & 0,100 & 0,100 \\
\hline Supl. mineral ${ }^{3}$ & 0,050 & 0,050 & 0,050 & 0,050 \\
\hline Antioxidante ${ }^{4}$ & 0,010 & 0,010 & 0,010 & 0,010 \\
\hline Sal & 0,311 & 0,310 & 0,310 & 0,310 \\
\hline Bicarbonato de sódio & 0,343 & 0,344 & 0,345 & 0,347 \\
\hline Inerte $^{5}$ & 0,060 & 0,060 & 0,060 & 0,060 \\
\hline L-treonina & 0,041 & 0,000 & 0,000 & 0,000 \\
\hline \multicolumn{5}{|l|}{ Valor calculado } \\
\hline Proteína bruta & 15,617 & 15,617 & 15,617 & 15,617 \\
\hline $\begin{array}{l}\text { Energia metabolizável } \\
(\mathrm{kcal} / \mathrm{kg})\end{array}$ & 2,750 & 2,750 & 2,750 & 2,750 \\
\hline Gordura & 3,203 & 3,884 & 4,577 & 5,270 \\
\hline Cálcio (\%) & 4,200 & 4,200 & 4,200 & 4,200 \\
\hline Fósforo disponível & 0,375 & 0,375 & 0,375 & 0,375 \\
\hline Metionina digestível ${ }^{6}$ & 0,406 & 0,407 & 0,408 & 0,409 \\
\hline Metionina total ${ }^{6}$ & 0,429 & 0,431 & 0,433 & 0,436 \\
\hline $\begin{array}{l}\text { Metionina + cistina } \\
\text { digestível }\end{array}$ & 0,694 & 0,696 & 0,698 & 0,700 \\
\hline $\begin{array}{l}\text { Metionina + cistina } \\
\text { total }\end{array}$ & 0,630 & 0,630 & 0,630 & 0,630 \\
\hline Lisina digestível & 0,718 & 0,718 & 0,718 & 0,718 \\
\hline Lisina total & 0,803 & 0,805 & 0,807 & 0,809 \\
\hline Treonina digestível & 0,556 & 0,513 & 0,507 & 0,501 \\
\hline Treonina total & 0,641 & 0,596 & 0,592 & 0,587 \\
\hline Arginina digestível & 0,916 & 0,921 & 0,925 & 0,928 \\
\hline Arginina total & 0,980 & 0,988 & 0,993 & 0,997 \\
\hline Triptofano digestível & 0,161 & 0,162 & 0,162 & 0,162 \\
\hline Triptofano total & 0,180 & 0,181 & 0,182 & 0,182 \\
\hline Valina digestível & 0,637 & 0,633 & 0,628 & 0,623 \\
\hline Valina total & 0,721 & 0,721 & 0,718 & 0,716 \\
\hline Fibra bruta & 2,553 & 2,733 & 2,910 & 3,087 \\
\hline Sódio (\%) & 0,250 & 0,250 & 0,250 & 0,250 \\
\hline Potássio & 0,593 & 0,601 & 0,608 & 0,614 \\
\hline Cloro & 0,220 & 0,220 & 0,22 & 0,22 \\
\hline
\end{tabular}

${ }^{1}$ Recomendações de Rostagno et al. (2000).

2 Composição por quilo do produto: vit. A - 10.000 .000 UI; vit. $D_{3}-2.500 .000 \mathrm{UI}$ vit. E - 6.000 Ul; vit. K - 1,6 g; vit. $B_{12}-11.000$ mcg; niacina - 2,5 g; ácido fólico - 0,4 g; ácido pantotênico - $10 \mathrm{~g}$; Se - 0,3 g; veículo - q.s.p.

${ }^{3}$ Micromin - suplemento mineral para aves. Composição por kg do produto.

$\mathrm{Mn}-150 \mathrm{~g} ; \mathrm{Zn}-100 \mathrm{~g} ; \mathrm{Fe}-100 \mathrm{~g} ; \mathrm{Cu}-16 \mathrm{~g} ; \mathrm{I}-1,5 \mathrm{~g}$; veículo - q.s.p.

${ }^{4}$ Antioxidante $=$ BHT (Beta-hidroxi-tolueno).

5 Inerte: areia lavada.

PB), todas formuladas de acordo com recomendações de Rostagno et al. (2000). A inclusão do complexo enzimático foi feita por meio da substituição de $60 \mathrm{~g}$ do material inerte e $40 \mathrm{~g}$ do milho das dietas.

As aves receberam água e ração à vontade durante todo o período experimental e, a cada um dos três períodos de 28 dias, todos os animais e as sobras de ração, por parcela, foram pesados.
As variáveis estudadas foram consumo de ração (CR), peso vivo final (PVF), produção (PR), peso do ovo (PO), massa de ovos (MO), conversão por massa (CMO), conversão por dúzia de ovos e gravidade específica (GE) da casca dos ovos.

O ganho de peso foi calculado pela diferença entre o peso final e o inicial; e o consumo alimentar, pela diferença entre a quantidade da ração fornecida e as sobras obtidas dos comedouros e baldes. A produção de ovos foi obtida em porcentagem por ave por dia (\%/ave/dia). O peso dos ovos correspondeu ao valor médio do peso dos ovos produzidos nos últimos três dias de cada fase experimental. A massa de ovos representou o produto da porcentagem de ovos produzida pelo peso médio dos ovos, enquanto a conversão alimentar por massa de ovos foi expressa em quilos de ração por quilo de massa de ovos produzida e a conversão alimentar por dúzia de ovos foi representada pela relação entre a quantidade de ração consumida $(\mathrm{kg})$ por dúzia de ovos produzida. A gravidade específica foi determinada pelo método da flutuação dos ovos em 15 soluções salinas, com variação da densidade em 0,0025 unidades, iniciando por 1,0625 até 1,100. Para isso, foram utilizados 15 baldes com capacidade de 50 litros, um densímetro de petróleo com escala de 1,050 a 1,100, uma cesta de plástico (balde vazado), água e sal comum. As avaliações foram realizadas sempre nos últimos três dias de cada fase experimental. As aves mortas e as sobras das dietas foram consideradas para ajustar o consumo, a produção de ovos e as conversões alimentares.

As análises estatísticas foram realizadas utilizando-se o programa SAEG (Euclydes, 1983). Após a análise de variância, o efeito dos níveis de farelo de trigo e do complexo enzimático sobre os resultados das variáveis foram avaliados pelo teste Student-Newman-Keuls $(\mathrm{P}<0,05)$. Posteriormente, as somas de quadrados dos efeitos do farelo de trigo foram decompostas nos efeitos lineares, quadráticos e cúbicos e, na escolha dos modelos de regressões, foram considerados o nível de significância, o coeficiente de determinação $\left(\mathrm{r}^{2}\right)$ e a resposta biológica das aves.

\section{Resultados e Discussão}

O consumo de ração, o peso vivo final, a produção, o peso e a massa de ovos e a conversão por massa e por dúzia de ovos não foram afetados $(\mathrm{P}>0,05)$ pela inclusão do farelo de trigo nas dietas (Tabela 2). A gravidade específica piorou $(\mathrm{P}<0,06)$ linearmente com a inclusão do farelo de trigo nas dietas (Figura 1).

A adição do complexo enzimático não afetou $(\mathrm{P}>0,05)$ o consumo de ração, o peso vivo final, a produção de ovos, 
Tabela 2 - Consumo de ração (CR), peso vivo final (PVF), produção de ovos (PR), peso do ovo (PO), massa de ovos (MO) conversão por massa de ovos (CMO), conversão por dúzia de ovos (CDZ) e gravidade específica (GE) dos ovos de poedeiras alimentadas com rações contendo farelo de trigo (FT) e complexo enzimático (CE)

\begin{tabular}{|c|c|c|c|c|c|c|c|c|}
\hline & $\mathrm{CR}, \mathrm{g} / \mathrm{dia}$ & PVF, kg & $\mathrm{PR}, \%$ & $\mathrm{PO}, \mathrm{g}$ & MO, g & $\mathrm{CMO} \mathrm{kg/kg}$ & $\mathrm{CDZ} \mathrm{kg/dz}$ & $\mathrm{GE}, \mathrm{g} / \mathrm{cm}^{3}$ \\
\hline \multicolumn{9}{|l|}{$\% \mathrm{FT}$} \\
\hline 0 & 101,960 & 1,748 & 74,620 & 63,620 & 47,510 & 2,162 & 1,760 & 1,0886 \\
\hline 3 & 99,010 & 1,731 & 74,390 & 63,830 & 47,500 & 2,089 & 1,656 & 1,0879 \\
\hline 6 & 98,580 & 1,724 & 73,710 & 63,170 & 46,530 & 2,121 & 1,692 & 1,0883 \\
\hline 9 & 96,880 & 1,717 & 73,250 & 63,410 & 46,480 & 2,088 & 1,669 & 1,0866 \\
\hline \multicolumn{9}{|l|}{$\mathrm{CE}$} \\
\hline 0,00 & 100,700 & 1,714 & 75,190 & $62,740 \mathrm{~b}$ & 47,180 & 2,142 & 1,671 & 1,0776 \\
\hline 0,05 & 97,510 & 1,746 & 72,800 & $64,280 \mathrm{a}$ & 46,830 & 2,088 & 1,717 & 1,0881 \\
\hline \multicolumn{9}{|l|}{ Anova } \\
\hline FT & $\mathrm{ns}$ & $\mathrm{ns}$ & ns & $\mathrm{ns}$ & $\mathrm{ns}$ & ns & ns & $(\mathrm{P} \leq 0,06)$ \\
\hline $\mathrm{CE}$ & $\mathrm{ns}$ & $\mathrm{ns}$ & $\mathrm{ns}$ & $(\mathrm{P} \leq 0,05)$ & $\mathrm{ns}$ & $\mathrm{ns}$ & ns & $\mathrm{ns}$ \\
\hline $\mathrm{FT} \times \mathrm{CE}$ & $\mathrm{ns}$ & $\mathrm{ns}$ & $\mathrm{ns}$ & ns & ns & $\mathrm{ns}$ & ns & $\mathrm{ns}$ \\
\hline CV\% & 8,048 & 4,334 & 8,060 & 4,008 & 9,852 & 6,964 & 11,211 & 0,208 \\
\hline
\end{tabular}

a,b Médias nas colunas seguidas de letras minúsculas distintas são diferentes pelo teste $S N K(P \leq 0,05)$.

ns $=$ não-significativo.

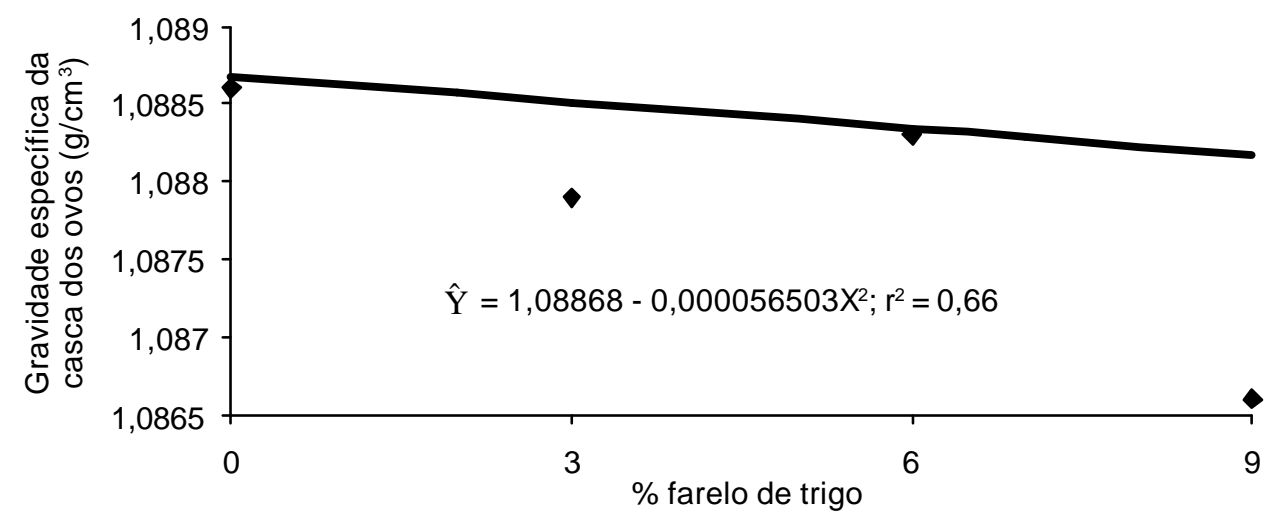

Figura 1 - Gravidade específica da casca dos ovos de poedeiras alimentadas com rações contendo farelo de trigo.

a massa de ovos, a conversão por massa e por dúzia de ovos e a gravidade específica. $\mathrm{O}$ peso dos ovos melhorou $(\mathrm{P} \leq 0,05)$ aproximadamente $2,45 \%$ quando o complexo enzimático foi adicionado às rações.

Álvarez \& Basilio (1999) avaliaram o efeito da adição de um complexo enzimático ( $\alpha$-glucanases, hemicelulase e pentosanase) em dietas com diferentes níveis $(0,15,30$ e $45 \%$ ) de farelinho de trigo sobre a digestibilidade e o valor energético em galos adultos. Os resultados comprovaram que a suplementação com o complexo enzimático aumentou significativamente $(\mathrm{P} \leq 0,001)$ a digestibilidade da matéria seca, da fibra em detergente neutro, da fibra em detergente ácido e do extrato etéreo em 6,$4 ; 13,9 ; 14$ e 22,5\%, respectivamente. Segundo esses autores, a concentração de PNA no farelinho de trigo, subproduto do processo de moenda do trigo, deve ser consideravelmente aumentada pela extra- ção do endosperma do grão de trigo, causando aumento da viscosidade da digesta, em virtude da alta capacidade de formação de gel das cadeias longas deste tipo de PNA. O mesmo foi observado neste estudo para farelo de trigo, uma vez que esse subproduto é formado portecidos botânicos distintos exteriores ao núcleo do grão do trigo, como o pericarpo (película que recobre o grão), a testa (película que recobre a semente), a camada hialina e a aleurona; essas duas últimas são partes externas ao endosperma e, assim como no farelinho, são extraídas no processo de moenda.

Neste estudo, a digestibilidade dos nutrientes da dieta pode ter sido aumentada pela adição do complexo enzimático, em virtude do aumento do peso dos ovos.Essa hipótese ratifica a afirmação de Álvarez \& Basilio (1999) de que, mesmo com a piora do desempenho causada pelos PNA, a adição das enzimas promoveu a recuperação do 
valor energético que seria perdido com a inclusão do farelinho de trigo.

Os resultados obtidos neste estudo contrariam os encontrados por Araujo (2005) e Araujo et al. (2008), que, em pesquisa com frangas de reposição semipesadas de 7 a 14 semanas alimentadas com rações contendo $0,10,20$ e $30 \%$ de farelo de trigo, observaram redução de 0,03 g no ganho de peso e de aproximadamente $1,15 \mathrm{~g}$ no peso vivo final a cada $1 \%$ de farelo de trigo adicionado à ração. Esses autores relacionaram esses resultados ao aumento de aproximadamente $40 \%$ no teor de fibra.

Araujo (2005) e Araujo et al. (2005, 2008), no entanto, em pesquisa com frangas semipesadas alimentadas no período de 14 a 19 semanas de idade com dietas contendo 0, 10, 20 e 30\% de farelo de trigo e dois níveis de um complexo enzimático comercial (amilase, protease e celulase), observaram que o consumo de ração, o peso do ovo e a gravidade específica do ovo não foram afetados pela adição do farelo e trigo, independentemente da suplementação com complexo enzimático. De acordo com esses autores, o complexo enzimático não teve influência significativa $(\mathrm{P}>0,05)$ sobre nenhuma das variáveis estudadas, entretanto, a massa de ovos reduziu de forma linear, $0,13 \mathrm{~g} /$ dia para cada $1 \%$ de aumento do farelo de trigo na $\operatorname{dieta}\left(\hat{Y}=44,9065-0,132645 X ; r^{2}=0,77\right)$, e a conversão por massa de ovos apresentou comportamento quadrático de acordo com o aumento do nível de farelo de trigo na ração ( $\left.\hat{\mathrm{Y}}=3,41107-0,0947473 \mathrm{X}+0,000920176 \mathrm{X}^{2} ; \mathrm{r}^{2}=0,98\right) . \mathrm{O}$ nível ótimo de inclusão do farelo de trigo, segundo esses autores, foi de $8,01 \%$ e a conversão por dúzia de ovos também piorou linearmente $(\mathrm{P} \leq 0,05)$ com o aumento dos níveis de farelo de trigo na ração.

Os resultados obtidos neste estudo foram similares aos descritos por esses resultados, exceto para a gravidade específica, que piorou $(\mathrm{P} \leq 0,06)$ linearmente com o aumento do nível de farelo de trigo na ração. Como no processo de moenda do trigo o rompimento das paredes celulares libera ácido fítico (Helsby et al., 2000), que atua como ligante de cátions bivalentes como o $\mathrm{Ca}$ e o $\mathrm{P}$, indisponibilizando aproximadamente dois terços desses nutrientes em ingredientes de origem vegetal, é possível que tenha havido interação entre o ácido fítico liberado e estes minerais, importantes para a formação da casca do ovo, piorando a densidade específica da casca dos ovos.

Fireman et al. (1999), estudando os efeitos da inclusão de farelo de arroz desengordurado, com ou sem adição de fitase, sobre a qualidade dos ovos de galinhas poedeiras, encontraram resultados semelhantes; ou seja, piora da gravidade específica da casca dos ovos com a inclusão do ingrediente testado. Esses autores também relataram influência negativa no aproveitamento dos cátions, como o Ca, e elevação do teor de ácido fítico, o que não ocorreu quando adicionada a enzima fitase às dietas.

Dois fatores podem explicar as diferenças entre os resultados deste estudo e os obtidos por Araujo (2005) e Araujo et al. $(2005,2008)$ : primeiro, o nível máximo de farelo de trigo na dieta de postura foi de até $9 \%$, enquanto nos trabalhos com frangas de reposição foram de até 30\%; segundo, as aves estavam em diferentes estádios fisiológicos no momento em que foram fornecidas as rações com farelo de trigo. Além disso, as aves almentadas com rações contendo até $30 \%$ de farelo de trigo ainda estavam na fase de reposição (entre 7 e 19 semanas de idade), enquanto aquelas alimentadas com as dietas com até $9 \%$ de farelo de trigo estavam em postura. A maturidade fisiológica do trato gastrointestinal dos animais é um importante fator a ser observado para adequar os níveis de alimentos alternativos nas dietas à capacidade digestiva das aves, principalmente se os nutrientes destes alimentos forem de baixa digestibilidade.

Boros et al. (2002), por exemplo, avaliaram o desempenho de frangos de corte alimentados com dietas contendo grão ou diferentes frações, como o farelo e a farinha de centeio, um alimento tão rico em arabinoxilans quanto o farelo de trigo, com a adição de um complexo enzimático (celulase, glucanase e xilanase) e observaram melhora progressiva da conversão alimentar, que foi de 4,02 na primeira, 3,09 na segunda e 2,97 na terceira semana de vida dos animais, quando não adicionado complexo enzimático nas dietas com frações de centeio. Entretanto, com a adição do complexo enzimático, a conversão alimentar variou pouco (entre 2,50 e 2,59 da primeira à terceira semana), o que comprova melhora na conversão alimentar com a inclusão do complexo enzimático e adaptação dos animais às rações com o avançar da idade. Portanto, pode-se afirmar que as poedeiras utilizadas neste estudo estavam fisiologicamente mais preparadas para digerir os nutrientes do farelo de trigo, em comparação àquelas utilizadas por Araujo (2005) e Araujo et al. (2008), e puderam aproveitar melhor os nutrientes, em virtude dos níveis reduzidos de farelo de trigo na ração.

\section{Conclusões}

A utilização de até $9 \%$ de farelo de trigo na alimentação de poedeiras semipesadas em produção é nutricionalmente viável, embora piore a gravidade específica da casca dos ovos. A adição do complexo enzimático contendo $\alpha$-galactosidase, galactomananase, xilanase e $\beta$-glucanase 
melhora o peso dos ovos de poedeiras semipesadas alimentadas com rações contendo farelo de trigo.

\section{Agradecimento}

Ao Dr. André Moreira Bordinhon, pelas correções do abstract.

\section{Literatura Citada}

ÁLVAREZ Z,R.; BASILIO, V. Índices digestivos en aves con dietas de afrechillo de trigo y enzimas exógenas. Revista de la Facultad de Ciencias Veterinarias de la Universidad Central de Venezuela, v.40, n.4, p.233-242, 1999.

ARAUJO, D.M. Avaliação do farelo de trigo e enzimas exógenas na alimentação de frangas e poedeiras. Areia: Universidade Federal da Paraíba, 2005. 81p. Dissertação (Mestrado em Zootecnia) - Universidade Federal da Paraíba, 2005.

ARAUJO, D.M.; SILVA, J.H.V.; ARAUJO, J.A. et al. Inclusão do farelo de trigo e de um complexo enzimático na ração de recria de frangas semipesadas. In: REUNIÃO ANUAL DA SOCIEDADE BRASILEIRA DE ZOOTECNIA, 42., 2005, Goiânia. Anais... Goiânia: Sociedade Brasileira de Zootecnia, 2005. (CD-ROM).

ARAUJO, D.M.; SILVA, J.H.V.; ARAUJO, J.A. et al. Farelo de trigo na alimentação de poedeiras semipesadas na fase de recria. Revista Brasileira de Zootecnia, v.37, n.1, p.67-72, 2008.

BEAUGRAND, J.; CRÔNIER, D.; DEBEIRE, P . et al. Arabinoxylan and hydroxycinnamate content of wheat bran in relation to endoxylanase susceptibility. Journal of Cereal Science, v.40, p.223-230, 2004.

BEDFORD, M.R. Exogenous enzymes in monogastric nutrition their current value and future benefits. Animal Feed Science and Technology, v.86, p.1-13, 2000.

BEDFORD, M.R.; PARTRIDGE, G.G. Enzymes in farm animal nutrition. Marlborough: CABI Publishing; Finnfeeds International, 2001. p.432.

BOROS, D.; MARQUARDT, R.R.; GUENTER, W. et al. Chick adaptation to diets based on milling fractions of rye varying in arabinoxylans content. Animal Feed Science and Technology, v.101, p.135-149, 2002.

EUCLYDES, R.F. SAEG - Sistema para análise estatística e genética Versão 5.0. Viçosa, MG: Universidade Federal de Viçosa 1993. 59p.
FIREMAN, A.K.B.A.T.; LÓPEZ, J.; FIREMAN, F.A.T. Qualidade da casca do ovo de poedeiras alimentadas com diferentes níveis de farelo de arroz desengordurado e fitase. Archivos Latinoamericanos de Produción Animal, v.7, n.2, p.97$108,1999$.

HELSBY, N.A.; ZHUA, S.; PEARSON, A.E. Antimutagenic effects of wheat bran diet through modification of xenobiotic metabolising enzymes. Mutation Research, v.454, p.77-88, 2000 .

MAES, C.; VANGENEUGDEN, B.; DELCOUR, J.A. Relative activity of two endoxylanases towards water-unextractable arabinoxylans in wheat bran. Journal of Cereal Science, v.39, p.181-186, 2004.

MARQUARDT, R.R.; BRENES, A.; ZHANG, Z. et al. Use of enzymes to improve nutrient availability in poultry feedstuffs. Animal Feed Science Technology, v.60, p.321-330, 1996.

MATHLOUTHI, N.; JUIN, H.; LARBIER, M. Effect of xylanase and â-glucanase supplementation of wheat- or wheat- and barleybased diets on the performance of male turkeys. British Poultry Science, v.44, n.2, p.291-298, 2003a.

MATHLOUTHI, N.; MOHAMED, M.A.; LARBIER, M. Effect of enzyme preparation containing xylanase and â-glucanase on performance of laying hens fed wheat/barley- or maize/soybean meal-based diets. British Poultry Science, v.44, p.60-66, 2003b.

ROSTAGNO, H.S.; ALBINO, L.F.T.; DONZELE, J.L. et al. Tabelas brasileiras para suínos e aves: composição de alimentos e exigências nutricionais. Viçosa, MG: Universidade Federal de Viçosa, 2000. 141p.

ROSTAGNO, H.S.; ALBINO, L.F.T.; DONZELE, J.L. et al. Tabelas brasileiras para suínos e aves: composição de alimentos e exigências nutricionais. 2.ed. Viçosa: MG: Universidade Federal de Viçosa, 2005. 186p.

SILVA, J.H.V.; MUKAMI, F.; ALBINO, L.F.T. Uso de rações à base de aminoácidos digestíveis para poedeiras. Revista Brasileira de Zootecnia, v.29, n.5, p.1446-1451, 2000.

SILVA, S.S.P.; SMITHARD, R.R. Effect of enzyme supplementation of a rye-based diet on xylanase activity in the small intestine of broilers, on intestinal crypt cell proliferation and on nutrient digestibility and growth performance of the birds. British Poultry Science, v.43, p.274-282, 2002.

YIN, Y.-L.; MCEVOY, J.D.G.; SCHULZE, H. Apparent digestibility (ileal and overall) of nutrients and endogenous nitrogen losses in growing pigs fed wheat (var. Soissons) or its by-products without or with xylanase supplementation. Livestock Production Science, v.62, p.119-132, 2000. 